\title{
Persistent Organic Pollutants (POPs) in the focus of science and politics
}

\section{Other Journal Item}

\section{Author(s):}

Scheringer, Martin

Publication date:

2004-01

Permanent link:

https://doi.org/10.3929/ethz-b-000051516

Rights / license:

In Copyright - Non-Commercial Use Permitted

Originally published in:

Environmental Science and Pollution Research 11(1), https://doi.org/10.1007/BF02980278 


\title{
Editorial
}

\section{Persistent Organic Pollutants (POPs) in the Focus of Science and Politics}

\author{
Martin Scheringer \\ Institute for Chemical and Bioengineering, Swiss Federal Institute of Technology Zürich, CH-8093 Zürich (scheringer@tech.chem.ethz.ch)
}

\section{Lessons Learned}

Environmental and human exposure to Persistent Organic Pollutants (POPs) has been the subject of scientific investigation and political regulation for almost 40 years. The signature of the Stockholm Convention on Persistent Organic Pollutants (http://www.pops.int) in May 2001, and the current process of the convention's ratification, is one of the most obvious and important results of this scientific and political discussion.

With the exception of the chlorinated dioxins and furans, the chemicals that are today classified as POPs were introduced in the 1950s as efficient insecticides and non-flammable multipurpose chemicals (polychlorinated biphenyls). Without doubt, these chemicals brought about a variety of benefits and, in this function, they were signals of the new enthusiasm concerning powerful chemicals that could be applied in a wide variety of contexts. On the other hand, POPs have caused significant damage to the environment and human health and, therefore, they are also signals showing the danger of neglected side-effects of technological progress.

Finally, in a function that was not initially intended, POPs have also served as 'model compounds' in environmental chemistry. A great deal of scientific and technical progress has evolved from the investigation of the environmental behavior of these chemicals, and of the possibilities to control and avoid their formation and/or release. Our improved understanding includes, for example, the processes of longrange transport in air and in ocean waters; the formation, transformation and degradation of POPs under a variety of conditions; the influence of temperature on mobility, degradability and volatility of POPs, leading to the phenomena of cold condensation and global fractionation; estimates of POPs emissions and, on this basis, regional or global mass budgets; the time scales of environmental contamination and of its decrease after emission reduction; improved combustion technologies; and technologies for the clean-up of contaminated sites and the destruction of POP stockpiles.

\section{Challenges for Environmental Research}

However, we have not only learned from the POPs case about environmental processes and technical solutions to POP contamination but we can also learn from the POPs case in a reflective manner about the role and tasks of environmental research.In particular, the POP case illustrates two important features of environmental research. First, environmen- tal research is related to political, economic and societal decision-making processes. To make its results fruitful for application in decision-making contexts, it is necessary to include these contexts - at least to some extent - already in the definition of research questions; otherwise, scientific results cannot be used efficiently by decision makers. However, the relationship between research and decision-making processes is not at all trivial, but constitutes a major challenge for research on the environmental behavior of POPs. It poses the question of how the independence and the internal objectives of scientific research can be reconciled with extra-scientific needs and objectives.

Because of the close link between science and politics, the series on POPs in ESPR and UWSF (Klöpffer and Scheringer 2000 , 2001) addresses both parts of the POPs case, scientific investigation as well as the negotiation and establishment of political solutions.

A second feature of research into the environmental behavior of POPs is that it has to deal with extremely complex systems. The complexity of environmental systems often impedes the application of results gained for a certain situation to other similar situations. In particular, it is often not clear whether laboratory results can reliably be extrapolated to field situations. In addition, the complexity of environmental systems implies that there are still large fields of nonknowledge or even ignorance (Hoffmann-Riem and Wynne 2002) containing an unknown number of unresolved processes and interdependencies. This non-knowledge is not simply a challenge for further research, but also constitutes a severe obstacle to the application of scientific results in nonscientific decision-making contexts.

These two features of the research on POPs - the high and often irreducible complexity of the subject investigated and the relationship to decision-making processes in other parts of society - have several implications:

- The complexity of the environmental systems in which POPs circulate and of the processes leading to the releases of POPs causes considerable gaps in our understanding of the environmental fate and the global budget of POPs.

In many cases, the emissions of a POP that have occurred over the last decades are known without sufficient sparial and temporal resolution. This uncertainty of the sources impedes the interpretation of measured concentrations because it is difficult to determine whether a certain concentration in the environment represents a 
recent or local signal or whether it is the residue of a long-lasting degradation process.

However, the gaps or inconsistencies in the global mass budgets of POPs are not only due to insufficient knowledge of the sources, but also derive from an incomplete understanding of the pathways and sinks in the environment. The importance of export to the deep ocean, for example, has only recently been elucidated. Another unresolved problem is the atmospheric fate of many POPs (and semivolatile organic chemicals in general). This includes a lack of experimental data on degradation of POPs in the gas phase and an incomplete understanding of the interaction of POPs with aerosol particles and degradation of the particle-bound fraction. Therefore, the influence of aerosol particles on the persistence and long-range transport of POPs is still uncertain. Other questions concern the influence of environmental media that are difficult to characterize, because of their strong variability and heterogeneity, such as different soil types, vegetation, or ice and snow.

- The needs on the political side make a stronger interaction and collaboration between scientists and users of scientific results desirable. Often, scientific results are presented in journal articles with the expectation that they will be taken up and put into practice by users in government and industry. However, because this process of dissemination is uncertain and slow, more efficient 'carriers' of scientific results and of political needs should be sought. One important type of such carriers is provided by specifically defined indicators of the environmental fate of chemicals. Such indicators have different functions: they help define the focus of scientific research, they provide scientific information in a condensed form, and they also reflect the political or normative relevance of a certain aspect of a chemical's environmental fate. Indicators that have become useful in the field of POPs, for example, are persistence and long-range transport potential, and the potential for cold condensation or arctic contamination (OECD 2002).

The set of POPs indicators, however, is not complete but needs to be further developed in a joint effort of scientists and users of scientific results. This includes the refinement of existing and the development of new indicators, the investigation of how indicators and chemical properties are related, and the clarification of whether indicators sufficiently reflect those aspects of human and environmental exposure to POPs that are normatively relevant.

When the scientific knowledge on POPs is delivered to political processes, this knowledge is necessarily condensed and combined with information on economic, technical, and legal aspects of POP control and replacement. This process of selecting and 'blending' different types of information requires a continuous evaluation of the scientific knowledge and feedback to the research process.

- A point related to the need for POPs indicators is that the uncertainties accompanying the results of environ- mental research need to be specified and communicated to those who employ these results. Often, this requires strenuous efforts to make the assumptions of a model or method transparent, and to clarify the implications that these assumptions have for the results of this research. Again, collaboration or exchange between scientists and users of scientific results will be helpful for identifying and making explicit the many uncertainties associated with our knowledge of POPs.

\section{The Touchstone: Additional POPs}

On the scientific side, there is an agenda full of tasks for POPs research. These include improvements of emission inventories, more comprehensive field measurements and monitoring activities, more extensive measurements of the substance properties of POPs, and a further development of multimedia models of the global fate of POPs. On this basis, the current POPs criteria used in various regulations can be continuously evaluated and, if necessary, improved so that they are most suitable for the identification of additional POPs.

This leads to the political part of the problem. Given our past experiences with POPs, it should be the most important goal to avoid similar cases with additional chemicals. However, increasing environmental and human exposure to polybrominated diphenyl ethers, hexabromocyclododecane, and perfluorooctane sulfonates demonstrates that there are other cases calling for action. Of course, this action should be based on scientific understanding, but it also requires a strong and timely effort to create a political mandate for processes leading to emission reductions.

As the co-editors of the POPs series in ESPR and UWSF, Walter KIöpffer and I look forward to further interesting contributions to both parts of the series, science and politics of POPs (see also Scheringer et al. 2004, this issue)

\section{References}

Hoffmann-Riem H, Wynne B (2002): In risk assessment, one has to admit ignorance. Nature 416: 123

Klöpffer W, Scheringer M (2000): Persistente Organische Schadstoffe (Persistent Organic Pollutants, POPs), UWSF - Z Umweltchem Ökotox 12: 307-309

Klöpffer W, Scheringer M (2001): How to Deal with Persistent Organic Pollutants? ESPR - Environ Sci \& Pollut Res 8: 63

OECD (2002): Report of the OECD/UNEP Workshop on the Use of Multimedia Models for Estimating Overall Environmental Persistence and Long-Range Transport in the Context of PBTs/ POPs Assessment. OECD, Paris, 191 pp

Scheringer M, Stroebe M, Wania F, Wegmann F, Hungerbühler $\mathrm{K}$ (2004): The Effect of Export to the Deep Sea on the Long-Range Transport Potential of Persistent Organic Pollutants. ESPR Environ Sci \& Pollut Res 11: 41-48 